\title{
Las centralidades urbanas en la contemporaneidad. Avances teóricos y metodológicos en clave de laboratorio
}

\author{
Urban centralities in contemporaneity. Theoretical and \\ methodological advances in laboratory key
}

\begin{abstract}
Eleonora Leicht Arocena ${ }^{1}$
http://orcid.org/0000-0001-7408-4452;

\section{Amancay Matos Santestevan ${ }^{2}$ Leonardo Gómez Sena ${ }^{3}$}

Primera versión recibida en: 23 mayo, 2019

Última versión recibida en: 13 octubre, 2019

\section{Resumen}

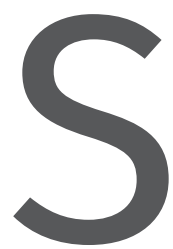

e presenta la investigación académica en curso cuyo eje son las centralidades urbanas. Un equipo multidisciplinario ad hoc creado en 2016, integrado por docentes con interés en la temática desde distin-

1 Investigadora Profesora adjunta en el Instituto de Teoría de Arquitectura y Urbanismo, Facultad de Arquitectura, Diseño y Urbanismo; Universidad de la República. Uruguay eleonoraleicht@gmail.com 2 Arquitecta, maestranda en Ordenamiento territorial. Investigadora en ITU, Universidad de la República amancay.matos@gmail.com 3 Arquitecto, docente investigador en el Instituto de Historia de la Arquitectura, Universidad de la República leonardogomez1966@gmail.com tos abordajes (urbano, histórico-patrimonial, socioeconómico, etcétera), lleva adelante esta investigación que se enriquece a través de la enseñanza y de la extensión en diversas modalidades.

Se exponen los avances de la investigación en los siguientes aspectos: la problematización y la revisión del concepto de centralidades en clave contemporánea, el sistema de centralidades en los instrumentos de ordenamiento territorial, los objetivos y abordaje metodológico del Laboratorio de Centralidades Urbanas y el ensayo de aplicación en el municipio A de Montevideo. El artículo culmina con algunos resultados y reflexiones hacia la construcción de una nueva mirada al sistema de centralidades.

\section{Abstract}

This article presents the research focused on the urban centralities, developed at the Universidad de la República, Uruguay. An ad hoc mul-

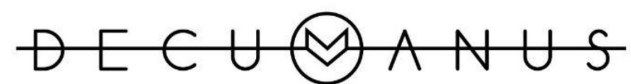

REVISTA INTERDISCIPLINARIA SOBRE ESTUDIOS URBANOS 
tidisciplinary team created in 2016, with interest in the subject from different approaches (urban, historical-heritage, socioeconomic, etc.), carries out this research that is enriched through teaching and extension in various modalities.

The advances of the investigation are exposed in the following aspects: the problematization and the revision of the concept of centralities in contemporary key, the system of centralities in the instruments of land planning, objectives and methodological approach of the Laboratory of Urban Centralities and the case study in Municipality A of Montevideo. The article ends with some outcomes and key-notes towards a new approach at the system of centralities.

Palabras clave: Centralidades, Planificación Urbana, Montevideo

Keywords: Centralities, Urban Planning, Montevideo

\section{El rol de las centralidades tradicionales en la contemporaneidad}

La constatación de la crisis a nivel mundial de los centros de barrio conocidos como centralidades es un tema reiterado en la literatura del urbanismo contemporáneo. Como alternativa se han propuesto estrategias tales como la reconquista de la calle y el espacio público en tanto lugar vital para el ciudadano, la gestión de áreas comerciales atendiendo a la diversidad de usos y actividades, la atención a los aspectos morfológicos y patrimoniales. En una escala más amplia, la recuperación de las centralidades se cita como una de las principales estrategias para alcanzar la ciudad compacta, el modelo más aceptado para el desarrollo urbano sostenible.

Según Lefebvre, la centralidad, para los que estudian el territorio es la esencia misma del fenómeno urbano. Lefebvre no la definía como un carácter estático, sino todo lo contrario, esto es, como un movimiento dialéctico que, a lo largo del tiempo, crea y cambia. La centralidad es aquel carácter de los lugares que permite que cada punto del territorio pueda ser un centro, caracterizar el entorno y llenarlo de sentido. Por ello, la centralidad no es un contenedor -un espacio definido- sino un contenido. ¿Qué es lo que lo compone? Según el sociólogo francés, la centralidad es una abundancia de objetos múltiples, yuxtapuestos, superpuestos, acumulados, pero también es el carácter de aquellos espacios donde la gente se empuja y se cruza (Paris, 2013).

A nivel internacional, la preocupación por los centros de barrio, está la peculiar modalidad de espacio que conjuga lo público y lo privado. Es una constante en textos clásicos de autores del urbanismo contemporáneo, tal como Philippe Panerai (1983) y su aproximación por la morfología y las atmósferas en su caracterización. También Jane Jacobs (1967) y Jan Gehl (2013) han subrayado la reconquista de la calle y el espacio público como lugar vital para el ciudadano. En una perspectiva más amplia, desde el paradigma de la sostenibilidad, Richard Rogers (2000) introduce el concepto de la ciudad compacta y desde allí a

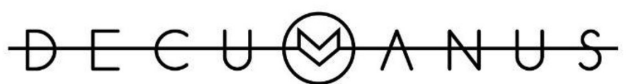

REVISTA INTERDISCIPLINARIA SOBRE ESTUDIOS URBANOS 
los centros barriales como elementos constitutivos de ella.

El concepto de ciudad compacta se identifica fundamentalmente con el modelo de ciudad medieval: urbes densamente construidas con espacios cívicos destacados, limitadas en su extensión por murallas defensivas. Rogers reinterpreta el modelo de ciudad densa e invita a profundizar en la idea de la ciudad compacta: una ciudad densa y socialmente diversa donde las actividades sociales y económicas se solapen y las comunidades puedan integrarse en su vecindario. Una ciudad sostenible puede ser, sostiene Rogers, una ciudad compacta y policéntrica, que proteja el campo circundante, centre e integre a las comunidades en el seno de sus barrios y optimice su proximidad. Complementariamente, le atribuye gran importancia al espacio público como lugar de encuentro de la diversidad y su potencial como factor de inclusión social. Los centros de barrio, tan singulares en Londres, son para Rogers un factor clave para fomentar la vitalidad y la densificación de la ciudad.

La bibliografía europea y norteamericana no suele abordar temáticas muy relevantes para las ciudades latinoamericanas como las relacionadas al comercio informal, cuyo abordaje requiere de una lectura no solo centrada en los mecanismos de los circuitos económicos, sino también en procesos de fragmentación social profundos. También en fenómenos culturales no solo ligados a estrategias de supervivencia sino a mecanismos de relacionamiento, pertenencia y visibilidad (Almeida dos Santos, 2015).
En Montevideo, las centralidades tradicionales se identifican con áreas comerciales y centros de barrio, en los que confluyen históricamente equipamientos y servicios tales como comercios, dependencias públicas, transporte, instituciones sociales y culturales, etcétera. Pese a las limitaciones de su escala, su condición de proximidad hizo posible su consolidación como referentes de esas comunidades locales. Las mismas aportaron de forma significativa al equilibrio territorial de la ciudad, evitaron desplazamientos hacia la centralidad principal (Centro, Ciudad Vieja) y contribuyeron a la identidad barrial, otorgándole vitalidad y carácter.

Según la relación con el proceso de consolidación de dichos barrios y de acuerdo con una lógica arraigada estas centralidades se articularon en torno a arterias o al encuentro de arterias, lo que determinó un vínculo histórico y muy fuerte con el espacio de la calle y definió su carácter público y urbano. Además de conformar un estructurador fundamental de la centralidad, la calle constituye, por su carácter de espacio público de proximidad, un territorio de particular simbiosis de los mundos de lo público y lo privado y en el que sus responsabilidades y competencias se vuelven imprecisas; ese espesor determina unas de las principales complejidades del abordaje de estas áreas.

Pese a la relevancia que estos centros urbanos adquirieron a lo largo del siglo $x x$, el escenario planteado por los espacios contemporáneos de consumo (shopping centers, gran-

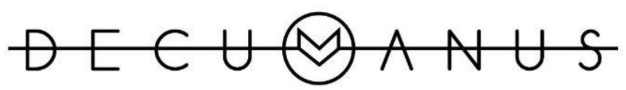

REVISTA INTERDISCIPLINARIA SOBRE ESTUDIOS URBANOS 
Figura 1. Centralidad de Paso Molino en época de fiestas, 28 de diciembre de 2017

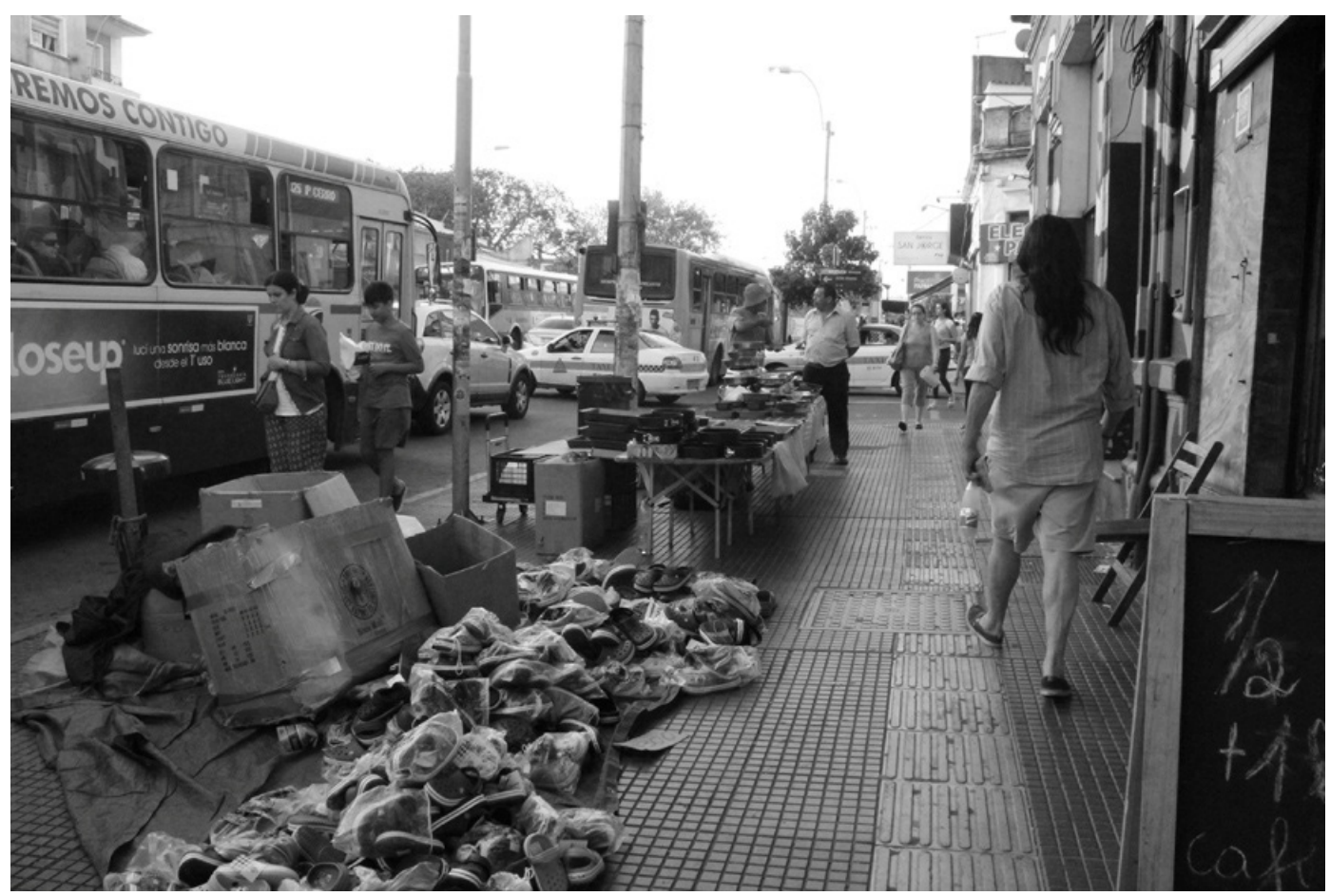

Fuente: Elaboración propia

des superficies) en las últimas tres décadas -que suponen además de cambios urbanos, nuevos comportamientos sociales y nuevas tendencias de consumo-, erosiona su rol urbano y sociocultural. Esto provoca, entre otros aspectos, un declive de la actividad comercial y cultural con la consecuente pérdida de vitalidad en ámbitos de encuentro y socialización.

Entre los factores que intervienen en el estado actual de las centralidades tradicionales se detectan la informalidad, la falta de seguridad, el diseño urbano deficitario, el excesivo tránsito y la falta de calidad ambiental.

Desde finales del siglo $x x$ el sector de la distribución comercial experimenta grandes transformaciones que responden y acompañan cambios aún más profundos que han tenido lugar a nivel de la economía, la sociedad, la tecnología y la cultura a nivel mundial. Ese nuevo contexto ha dado lugar a una complejización y especialización de roles y competencias dentro de los canales de distribución que transformó no solo las tipologías y formatos de los comercios, sino también los sistemas de asociación y distribución.

Es así como a partir del desarrollo de los denominados sistemas de distribución vertical (particularmente los corporativos) o dentro de las lógicas del comercio asociado (cadenas franquiciadas), grandes firmas comerciales conformaron cadenas de sucursales en escala mundial, que cuentan con presencia en las principales áreas y equipamientos comerciales del

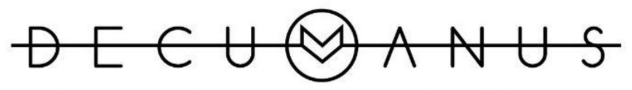

REVISTA INTERDISCIPLINARIA SOBRE ESTUDIOS URBANOS 
mundo. Dentro de las mecánicas del comercio asociado -y para completar este complejo escenario- tuvo lugar una acelerada expansión del formato de centros comerciales cerrados (sistemas horizontales espaciales), cuyo desarrollo a nivel mundial no solo modificó radicalmente las lógicas de competencia con el comercio minorista tradicional, sino que dio lugar a la conformación de nuevos lugares de centralidad. Los mismos constituyen espacios híbridos y complejos, donde existen edificios-contenedores y espacios libres gestionados por privados (Paris, 2013) que responden a nuevos modelos culturales y hábitos de consumo.

Cuando los procesos de expansión de estas multinacionales involucraron ejes comerciales y centralidades urbanas significativas, la conquista de ubicaciones estratégicas demostró la asimetría entre estas organizaciones empresariales y el comercio tradicional local, el que de forma prácticamente invariable fue sustituido o desplazado. Estas lógicas hegemonizaron y uniformizaron la oferta comercial de estas áreas (clone towns), restaron identidad y empobrecieron la experiencia del recorrido de estos enclaves urbanos valiosos y singulares.

La complejización y diversidad de ofertas de consumo, dadas por las nuevas lógicas del comercio mundial, generan nuevos espacios de consumo caracterizados por ser espacios controlados; esto sumado al comercio electrónico coopera a la desterritorialización del consumo y modifica el rol tradicional de las centralidades.
En síntesis, se identifica como problemática central la pérdida de prestigio que experimentan las centralidades urbanas tradicionales de Montevideo. Este proceso, que afecta tanto a las actividades comerciales y socioculturales como a los aspectos medioambientales, ha erosionado su función simbólica tradicional y su rol como ámbitos de referencia de las comunidades locales. Pese al aparente consenso respecto de su trascendencia para la ciudad y a la experiencia internacional en la materia, en el caso de Montevideo se registran escasos estudios recientes enfocados en su comprensión y puesta en valor.

La ausencia de una visión actualizada y de una estrategia integral dirigida a su abordaje deriva, en el campo de la actuación pública, en políticas y acciones parciales y débiles (donde muchas veces se reduce su problemática a temas de estricto orden urbano o normativo). En otros casos, en decisiones totalmente contrarias a esos postulados, lo que contribuye de forma directa -y quizás no intencional- a su proceso de degradación.

Dado que muchas veces esas acciones fueron además instrumentadas sin brindar los espacios adecuados para la participación e involucramiento de los actores directamente afectados, se entiende imprescindible como parte de una nueva mirada apostar a una jerarquización del papel de las comunidades locales vinculadas a estas áreas y a la promoción de nuevos modelos de gestión y de coparticipación.

En este sentido y como parte de la actualización conceptual se consi-

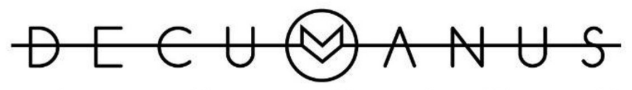

REVISTA INTERDISCIPLINARIA SOBRE ESTUDIOS URBANOS 
dera necesario atender a las amplias experiencias internacionales en esta materia (fundamentalmente en estas últimas tres décadas) mediante las cuales se desarrollaron modelos de colaboración público-privada dirigidos a regenerar y dinamizar centros urbanos, promover sinergias entre los agentes que los conforman y aportar soluciones concretas a las problemáticas más habituales (limpieza, mantenimiento, equipamiento urbano, seguridad, etcétera).

La lectura de estas experiencias y procesos implicarán una mirada necesariamente crítica, atenta no solo a las particularidades y problemáticas que enfrentan las centralidades urbanas de esta área de Montevideo, sino al contexto de un territorio marcado por desequilibrios territoriales y sus efectos sociales, económicos y ambientales. Las consecuencias de esa desarticulación del tejido social (donde la inseguridad pública ocupa un papel central) y el debilitamiento de una cultura de convivencia se conjugan con la pérdida de algunos de sus atractivos principales y afectan su carácter como ámbitos públicos de socialización.

El sistema de centralidades se visualiza como una oportunidad para densificar y revitalizar una ciudad que continúa expandiéndose sin aumento de población, que contribuya a la calificación urbana de los barrios y al afincamiento de población. Montevideo presenta condiciones excepcionales para la implementación de experiencias acotadas de cogestión (público-privado), reapropiación social y de promoción de buenas prácticas ciudadanas.

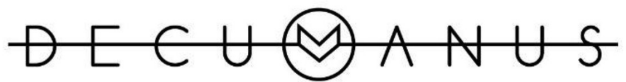

REVISTA INTERDISCIPLINARIA SOBRE ESTUDIOS URBANOS

\section{El sistema de centralidades en los Instrumentos de Ordenamiento Territorial}

\section{Las centralidades como sistema territorial del Plan de Ordenamiento Territorial de Montevideo}

En el contexto local, el Plan de Ordenamiento Territorial de Montevideo (РОT) aprobado en 1998 constituyó un primer esfuerzo para identificar, jerarquizar y mapear las centralidades, pero no se han revisado como sistema territorial, a excepción de los lineamientos generales que figuran en las Directrices Departamentales (2014), o las centralidades incluidas en el ámbito de planes parciales como Goes o Casavalle.

Las centralidades identificadas en el POT se clasifican en cuatro categorías que obedecen al proceso de conformación histórica de la ciudad y a distintos datos cuali y cuantitativos:

Figura 2. Ubicación y jerarquía de las centralidades

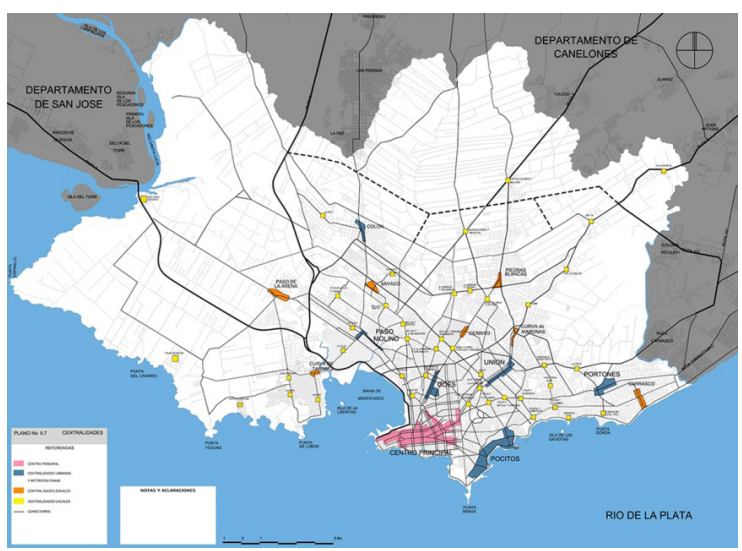

Fuente: Plan de Ordenamiento Territorial de Montevideo. Memoria de Ordenación (РОTIMM, 1998). 
- El centro principal, identificado como proyecto de valor estratégico en el POT y ratificado en las Directrices Departamentales.

- Las centralidades urbanas y metropolitanas, que agrupan a las que se consideran históricas (Goes, Unión y Paso Molino) y a otras que por su escala son de importancia metropolitana (Colón, Portones, Pocitos). Se registran seis de esta categoría.

- Las centralidades zonales, que responden a la necesidad de áreas comerciales vinculadas a crecimientos de la ciudad posteriores al surgimiento de las centralidades históricas. Se registran siete de esta categoría: Paso de la Arena, Curva de Tabárez, Sayago, Piedras Blancas, Cerrito, Curva de Maroñas, Carrasco.

- Las centralidades locales, que responden a una lógica de organización urbana que encuentra en la idea de barrio su fundamento cultural básico. Los centros locales son, más que una oferta de servicios, ámbitos espaciales en los cuales el colectivo materializa su autorrepresentación. Predomina el comercio de abastecimiento cotidiano. Se registran 42 centralidades locales.

Esta clasificación de las centralidades en el marco de la elaboración del POT denota la voluntad de posicionar la temática y dar respuesta a las transformaciones que se vivían en la década de los noventa vinculadas a la generación de nuevas áreas comerciales.

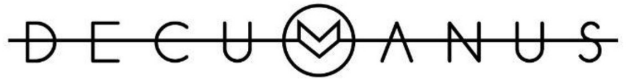

REVISTA INTERDISCIPLINARIA SOBRE ESTUDIOS URBANOS
Previo a que se elaboraran en la academia lineamientos para las centralidades en el marco del POT, se era testigo del impacto de la primera generación de shopping centers $\mathrm{y}$ de las transformaciones ocurridas en Montevideo (Urruzola, 1994). A nivel del sistema planificador de Montevideo se constata la existencia de numerosas ordenanzas, más de diez artículos dispersos en el capítulo IV del Digesto Departamental, con consecuencias significativas para la ciudadanía directamente relacionadas con las centralidades. Estas ordenanzas, entre otras cuestiones, habilitan el cerramiento del retiro frontal para usos comerciales dentro del área de la centralidad, o exigen más plazas de estacionamiento por el mismo motivo. Asimismo, el uso preferente en las centralidades es polifuncional, lo que habilita más flexibilidad en los usos que el habitacional con servicios complementarios, por ejemplo. La trascendencia asignada al sistema de centralidades como estructura territorial es de tal significación que la ejecución de una centralidad puede ser causal de expropiación.

Por otro lado, algunas centralidades fruto de iniciativa de la sociedad civil o agrupamientos comerciales espontáneos, no tienen un correlato en el Plan. A título de ejemplo, el Barrio de las Artes, el Bajo de Ciudad Vieja o el estructurador de la avenida Italia en determinados tramos -con cierta especialización en mercado automotor, decoración y artículos para el hogar- no tienen un registro en el sistema de centralidades "institucional" (de acuerdo a Plan). Tampoco son registrados a nivel instrumental los 


\section{Cuadro 1. La relevancia de las centralidades en el Digesto Departamental de Montevideo}

- $\quad$ Artículo D.179. Lineamientos para las centralidades:

- a) Promover un desarrollo policéntrico de la ciudad, consolidando los roles, características y potencialidades de las diversas centralidades, como forma de construir un soporte más rico e inteligente para la vida ciudadana.

- b) Calificar y promover la consolidación y desarrollo del conjunto de centralidades como estrategia para facilitar el acceso a servicios, equipamientos y recursos urbanos al conjunto de la población.

- $\quad$ Artículo D.223.75. Expropiación. La expropiación por razones de urbanismo:

- Para la ejecución de los sistemas territoriales de saneamiento, vialidad, espacios verdes, centralidades y equipamientos públicos.

- Cerramiento y uso de la zona de retiro frontal.

- Se permitirá el cerramiento y uso del área de retiro frontal únicamente en las centralidades y sobre los estructuradores:

- a) Bares, restoranes y similares. Como ampliación de locales de planta baja.

- b) Otros destinos comerciales. Se considerará la situación del entorno urbano y el aporte que la propuesta hace al mismo.

- Normas Complementarias: Condiciones de implantación de usos y actividades

- Artículo D.223.341. No se admite su implantación de Supermercados categoría 2b, en zonas residenciales salvo que se ubiquen sobre las vías de la jerarquización vial o en las centralidades establecidas en el Plan.

- $\quad$ Artículo D.223.349. Las viviendas, escritorios u oficinas que se localicen en la centralidad de Pocitos determinada en los gráficos del presente cuerpo normativo, les será de aplicación la disposición de 1 sitio de estacionamiento cada 2 unidades.

- $\quad$ Artículo D.223.351. Los comercios de abastecimiento diario y ocasional que se localicen en las centralidades de Pocitos, Punta Carretas, Unión, Paso Molino, Malvín y Colón, deberán contar con 1 sitio de estacionamiento cada 100 metros cuadrados.

- $\quad$ Artículo D.223.361. Servicios administrativos. Cuando la superficie total construida supere los 900 metros cuadrados los mismos deben ubicarse fuera de las zonas de uso preferente residencial, excepto en las centralidades o en las vías conectoras definidas en los gráficos del presente cuerpo normativo.

- $\quad$ Artículo D.223.362. Espectáculos y actos públicos. Cuando su capacidad supere los 500 concurrentes, los mismos deben ubicarse en las centralidades o en las vías conectoras definidas en los gráficos del presente cuerpo normativo.

- $\quad$ Artículo D.223.398. Explotación de minas y canteras. Estas actividades no podrán desarrollarse

- en el Área Ecológica Significativa, en el Área de la Costa Oeste de la Zonificación Secundaria ni en las Centralidades Rurales definidas en la presente norma.

- $\quad$ Artículo D.223.417. Educación y cultura. Los centros de enseñanza pre-escolar, primaria,

- $\quad$ secundaria, institutos o academias especializadas, podrán instalarse en los Estructuradores y en las Centralidades Rurales.

Fuente: Digesto Departamental de Montevideo, Volumen IV- Ordenamiento territorial, desarrollo sostenible y urbanismo

sectores especializados en determinados giros como el de repuestos a lo largo de la calle Galicia, o el de la venta al por mayor de ropa y accesorios en calle Colón o en Arenal Grande a la altura de Goes.

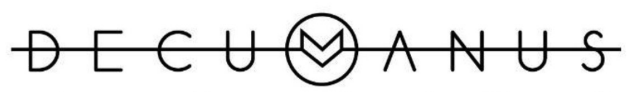

REVISTA INTERDISCIPLINARIA SOBRE ESTUDIOS URBANOS
Tratamiento de las Centralidades en los Instrumentos de Ordenamiento Territorial y Desarrollo Sostenible

Luego de la aprobación del рот Montevideo (1998) se desarrollaron estudios e Instrumentos de Ordenamiento Territorial y Desarrollo Sostenible 
enmarcados en la ley n.ㅇ 18.308 que incorpora el término de centralidades en diversos territorios y genera así ricos avances tanto desde el nivel conceptual como operativo que se propone analizar en la fase de desarrollo del presente proyecto. Con la aprobación de las Directrices Nacionales de Ordenamiento Territorial y Desarrollo Sostenible (ley n.o 19.525), el concepto de centralidad adquiere un importante papel. En efecto, los artículos 19 y 20 mencionan como lineamientos densificar y recalificar las centralidades urbanas.

Algunos de los casos significativos de tratamiento de las centralidades en el contexto de los instrumentos de ordenamiento a nivel nacional son el Costaplan en Canelones, los trabajos realizados por la Academia en convenio con la Intendencia de Maldonado sobre la aglomeración Maldonado-Punta del Este-San Carlos y el Plan de Ciudad del Plata en el departamento de San José. Estos casos resultan de interés ya que se relacionan con los procesos de urbanización del área metropolitana, y en el caso de Maldonado, con uno de los territorios de mayor dinámica poblacional y segundo polo metropolitano del país, en los cuales se constatan sectores de territorio periférico o con déficit de servicios y equipamiento, donde las centralidades se expresan como el espacio para el acceso a la ciudad, como oportunidad de reequilibrio territorial.

En Canelones el Costaplan (2007) realiza un importante aporte en la identificación y clasificación de centralidades e incorpora, a las ya utilizadas por el РОт Montevideo (1997) con respecto al área de influencia (metropolitano, urbano, local), la diferenciación por su carácter vinculado a los usos predominantes (centralidades comerciales, mixtas, o relacionadas a equipamiento específico, como educacional, cultural, entre otros). Define una metodología para su delimitación geográfica que incluye el relevamiento cuali y cuantitativo y desarrolla en la memoria de ordenación proyectos específicos para el fortalecimiento del sistema de centralidades.

En el caso de Ciudad del Plata se hace hincapié en la dependencia de centralidades de Montevideo como Santiago Vázquez y Paso de la Arena y en general al vínculo frecuente con la capital del país, con un incipiente proceso de afirmación de centralidades locales de carácter barrial en territorialidades emergentes en el área. Ciudad del Plata atraviesa procesos territoriales en el marco de cambios de mayor escala (metropolitano / internacional, metropolitano / zonal) lo cual tiene características asimilables en algunos aspectos a lo que ocurre en el Municipio A de Montevideo en su condición de sector periférico dentro del área metropolitana, donde la reflexión sobre el potencial del rol del sistema de centralidades emergentes vuelve a ser clave.

\section{Laboratorio de Centralidades Urbanas y Derecho a la Ciudad. Una experiencia piloto en el Municipio A}

El Laboratorio de Centralidades Urbanas surge como un espacio cons-

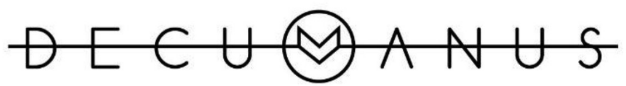

REVISTA INTERDISCIPLINARIA SOBRE ESTUDIOS URBANOS 
Figura 3. Presentaciones a los Espacios de Formación Integral 2016 y 2017
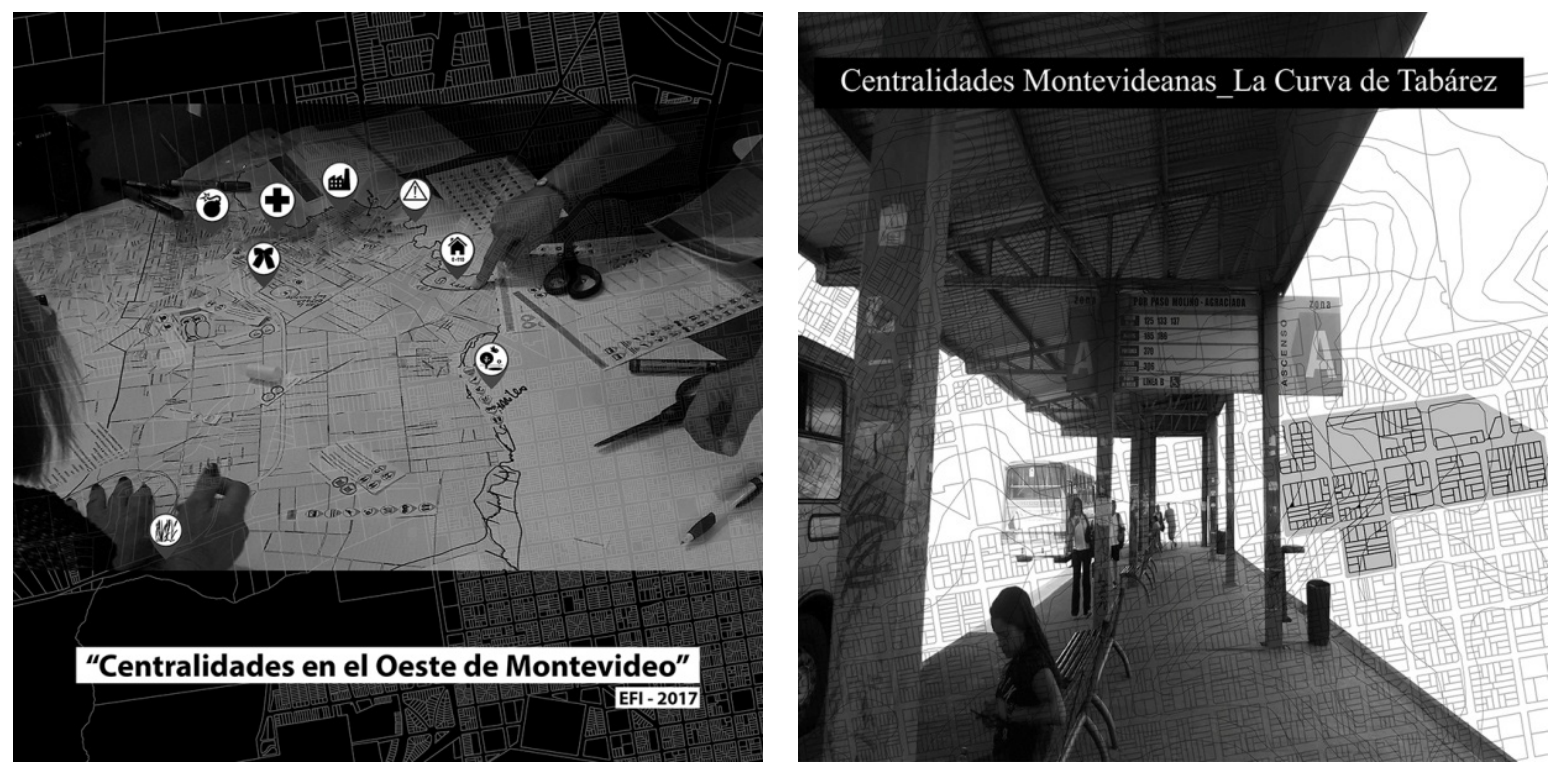

Fuente: Elaboración propia

truido desde el intercambio colectivo donde participan personas con diferentes grados de conocimiento y especialización. Por medio de diversas formas de experimentación y aprendizaje se comparten ideas, experiencias y vivencias, con el objetivo de generar conocimiento nuevo y producir intercambios sinérgicos. El formato "laboratorio" apunta a la promoción de ámbitos colaborativos y a la experimentación de nuevas metodologías de análisis y de actuación. Se fomenta el ensayo, el trasvasamiento disciplinar en torno a la búsqueda de los atributos de centralidad y de soluciones a los problemas que estos espacios enfrentan. El derecho a la ciudad, como derecho humano básico, requiere del cuidado y desarrollo de estos lugares de encuentro donde convergen diversas actividades económicas, recreativas, culturales, comerciales- y donde las personas no se presentan únicamente como consumidoras sino como ciudadanas y ciudadanos que puedan hacer uso pleno y apropiación de estos espacios.

Como criterio para definir el estudio de caso se estableció como prioridad el abordaje de centralidades vinculadas al territorio Oeste de Montevideo, sector en el que las centralidades tienen un papel relevante a cumplir dentro de una perspectiva de desarrollo equilibrado de la ciudad y del territorio nacional. En cualquier estadística de nivel nacional que indique valores respecto de la calidad de vida (educación, alimentación, vivienda, seguridad), el Municipio del Oeste figura "en rojo".

El Municipio A o "del Oeste" con 206547 habitantes, es uno de los municipios de Montevideo que integra el tercer nivel de gobierno según la ley de descentralización de 2009. Por

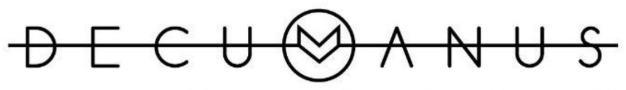

REVISTA INTERDISCIPLINARIA SOBRE ESTUDIOS URBANOS 
tanto, constituye un «territorio joven» en el que, si bien hay estudios e investigación, ninguno tiene la especificidad de su ámbito o recorte territorial. Es un territorio ávido de respuestas a los muchos problemas que enfrenta donde son relevantes las centralidades como parte de sus estructuras y sistemas territoriales.

\section{Cuadro 2. Objetivos del Laboratorio de Centralidades Urbanas}

Objetivos generales:

- Posicionar el concepto de centralidades urbanas como objeto de estudio, en tanto sistema territorial esencial de la planificación urbana.

- Visibilizar de manera integral al concepto de centralidades y su problemática a través de la investigación, enseñanza y extensión.

- Fomentar la interdisciplina y la integralidad de las funciones universitarias a través de la generación de un colectivo de trabajo en torno al formato "laboratorio".

Objetivos específicos:

- Generar nuevo conocimiento respecto del concepto centralidades a través del corpus casuístico del Municipio A como primera etapa de un estudio que a futuro podría replicarse en otros contextos.

- Cooperar con el equilibrio sociourbano del territorio montevideano a través del abordaje de las centralidades del Municipio $\mathrm{A}$, en tanto espacios públicos y potenciales motores de desarrollo económico local.

- Identificar atributos, potencialidades y singularidades de las diversas centralidades que se localizan en el Municipio A.

Fuente: Elaboración propia

Figura 4. Ubicación de las centralidades en el Oeste de Montevideo

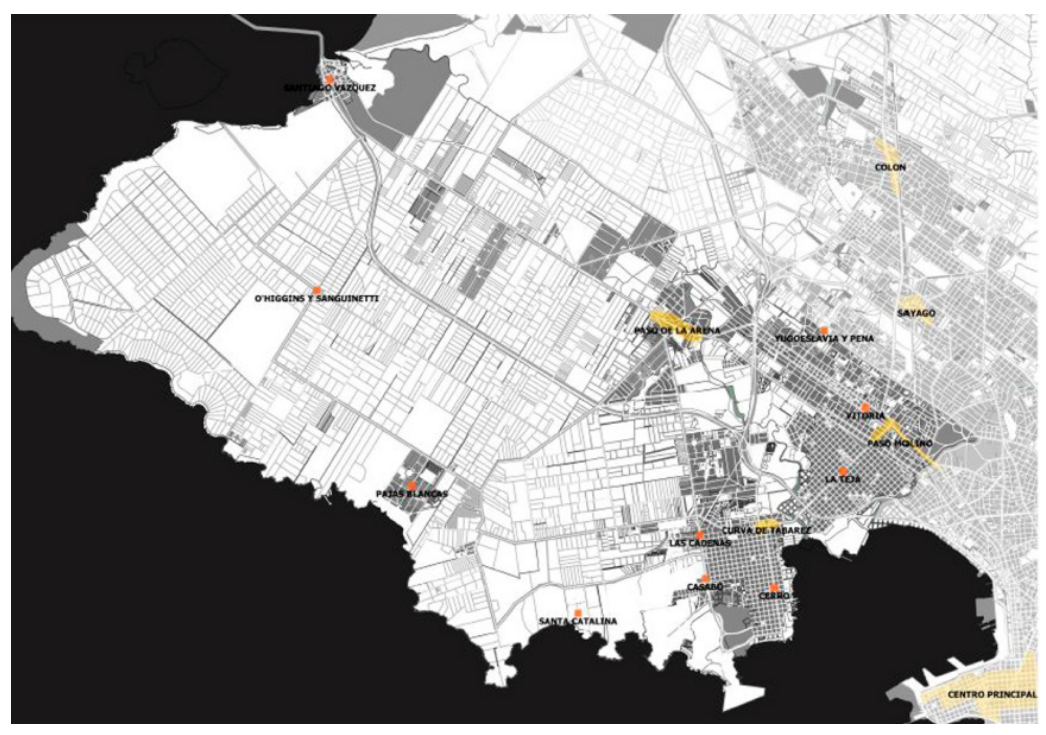

Fuente: Elaboración propia en base a cartografía SIG, Intendencia de Montevideo

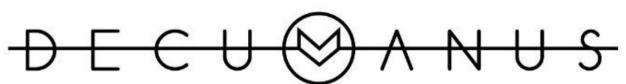

REVISTA INTERDISCIPLINARIA SOBRE ESTUDIOS URBANOS 
Se toma como punto de partida para el trabajo del Laboratorio el universo de las trece centralidades definidas en el РОт localizadas en el Municipio A:

Centralidad urbana-histórica

- Paso Molino

Centralidad zonal

- Paso de la Arena

- Curva de Tabárez

Centralidad local

- Santiago Vázquez

- La Teja (avenida Carlos María Ramírez)

- Calle Grecia

- Santa Catalina

- Pajas Blancas

- Casabó (calle Etiopía)

- Las Cadenas (Camino Cibils y avenida Carlos María Ramírez)

- Yugoeslavia y Pena (cruce de Yugoeslavia y Carlos María de Pena)

- Vitoria (Vitoria entre Santa Lucía y Julián Laguna)

Centralidad rural

- Camino O'Higgins y Sanguinetti

A partir de este estudio podrán identificarse nuevas centralidades a la luz del desarrollo que han tenido las áreas logísticas en los últimos quince años en el Municipio A, o ante las necesidades de suelos suburbanos habitacionales tipo enclave ( $\mathrm{Ba}-$ rrio Gori, Los Bulevares, por citar algunos). Asimismo se podrá analizar el impacto en el Municipio A de nuevas centralidades que se han desarrollado en la órbita metropolitana cercana, por ejemplo, el centro comercial de Las Piedras, grandes equipamien- tos cercanos inminentes como la Unidad Alimentaria, o cómo juega la centralidad de Ciudad del Plata articulada con Santiago Vázquez.

\section{Metodología de trabajo del Laboratorio}

\author{
Estrategias de abordaje \\ El plan de trabajo combina múltiples \\ estrategias de investigación, exten- \\ sión y enseñanza, entre las que se \\ subrayan:
}

\section{Trabajo de gabinete}

Se intercalan instancias de estudio bibliográfico en torno a dos aspectos:

a) El concepto de centralidad de acuerdo con distintos autores, tiempos y realidades. El auge y crisis de los centros urbanos.

b) El estudio de las centralidades del territorio del Municipio A en conexión con los demás elementos que integran sus sistemas y estructuras territoriales, tales como infraestructura vial, movilidad, saneamiento, equipamientos, espacios públicos. El Municipio A es un territorio complejo y heterogéneo, con gran superficie de suelo rural, la costa oeste aún prístina, pero por otro lado con enclaves tales como la Cárcel de Santiago Vázquez, el área de chacras marítimas La Baguala y numerosas áreas industriales y logísticas, entre ellas el Parque Tecnológico Industrial del Cerro (PTI).

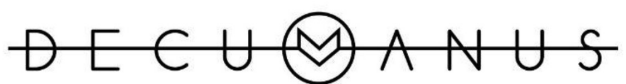

REVISTA INTERDISCIPLINARIA SOBRE ESTUDIOS URBANOS 
Figura 5. Salida de campo. Paso Molino, Santa Catalina, Santiago Vázquez, Paso de la Arena
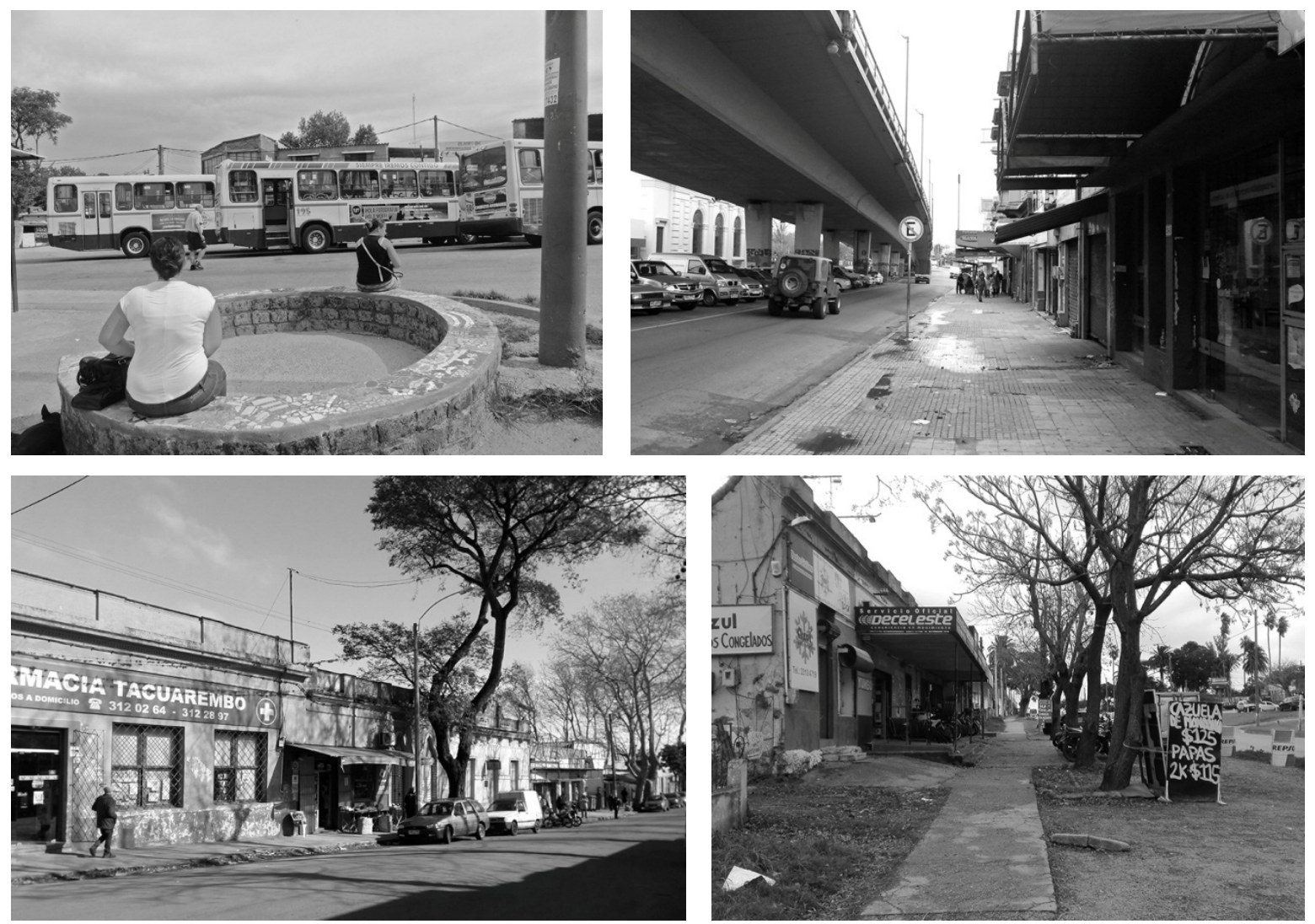

Fuente: Elaboración propia, 2017-18

Por medio de archivos históricos, literatura y entrevistas a habitantes añosos se realiza un análisis histórico que permite estudiar el surgimiento de las centralidades, su crecimiento o decrecimiento y transformaciones en el tiempo. En simultáneo se estudian los límites actuales y ámbitos de influencia de las centralidades, los usos del suelo, datos de población y vivienda, dinámicas comerciales, dinámicas de transporte y movilidad asociados. A su vez se identifican sus principales cualidades ambientales y morfológicas en términos de paisaje urbano, anchos de calles y veredas, alturas de las edificaciones, equipamiento existente, etcétera.

\section{Salida de campo}

Se realizan recorridas in situ para determinar los aspectos morfológicos así como también actividades comerciales, flujos de personas y de transporte, atmósferas. Nuevas herramientas informáticas como el Google Street View -sin sustituir la salida de campo- habilitan una verificación complementaria de los usos del suelo y aspectos morfológicos de forma más eficiente y abarcativa. Se organizó el equipo en cuadrillas con

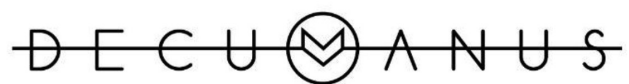

REVISTA INTERDISCIPLINARIA SOBRE ESTUDIOS URBANOS 
instrucciones y tareas concretas para optimizar la utilidad de la salida y el procesamiento de datos antes y después de ella.

Figura 6. Salida de campo. Instructivo para las cuadrillas

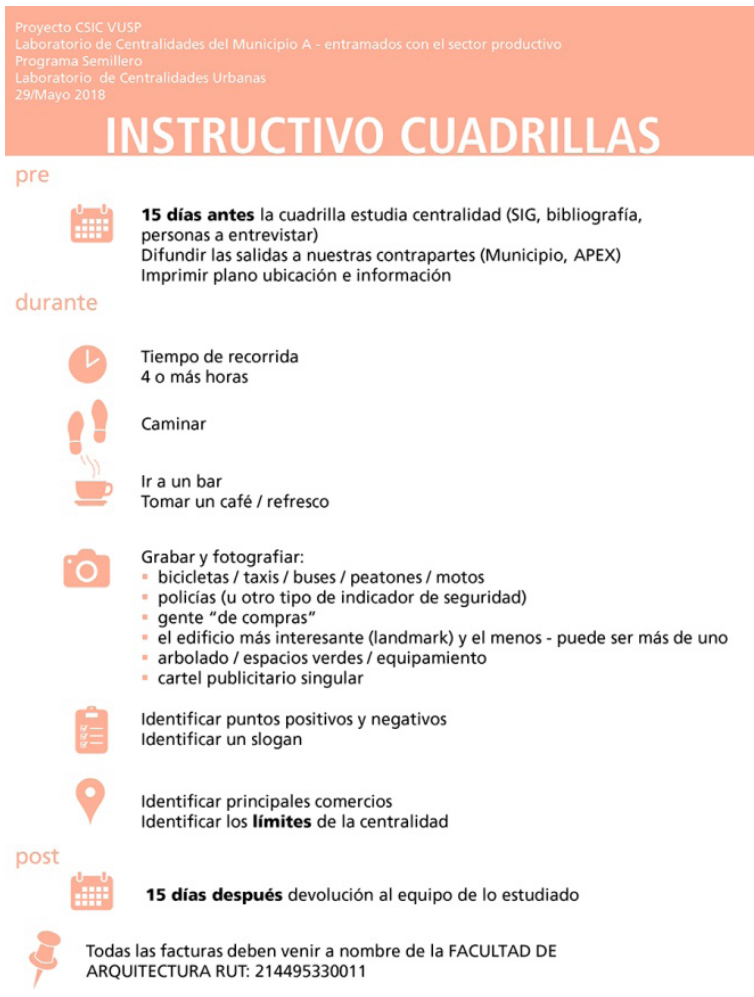

Fuente: Elaboración propia, 2018

\section{Entrevistas y encuestas}

Para conocer la percepción y opinión de diferentes actores en relación con las centralidades se decide utilizar una metodología de corte cualitativo, con diferentes abordajes, a través de técnicas de relevamiento de información que fueron analizadas en forma conjunta y complementaria.

Por un lado, se realizan encuestas en la vía pública, identificadas como "Encuestas de interceptación" por la profesora Derlis Daniela Parserisas, investigadora invitada por nuestro equipo por su trayectoria y trabajos en temas de mutuo interés. Esta modalidad de encuesta se aplicó a usuarios, vecinos y transeúntes de las centralidades, algunas en simultáneo a la salida de campo. Se identificaron actores barriales y locales clave en el territorio estudiado para, a partir de ello, realizar entrevistas semiestructuradas que aportan una visión de la cuestión tanto desde el ámbito público como del privado. El criterio de selección de personas a entrevistar se basó en la representación de las diversas áreas: urbano-territorial, comercial, sociocultural y educativa.

\section{Sinergia con procesos de aprendizaje proyectual contextualizado}

El trabajo coordinado entre los equipos docentes del Laboratorio y del Taller de Proyecto Urbano permitió que estudiantes y docentes se acercaran a la temática y que se realizaran trabajos finales de taller donde se problematizó las visiones a futuro en diferentes escenarios, se identificaron nuevos programas, equipamientos y usos posibles en las centralidades.

\section{Talleres colaborativos}

Por último, también se realizan talleres o jornadas de trabajo abiertas organizadas junto en territorio como forma de generar intercambio de ideas, profundizar en la articulación de las diferentes dinámicas existentes en la centralidad y divisar potenciales áreas de crecimiento y fortalecimiento. 
Imagen 9. Plano de Estación Nueva, Patio General-Patio de la Ciudad de Puebla.

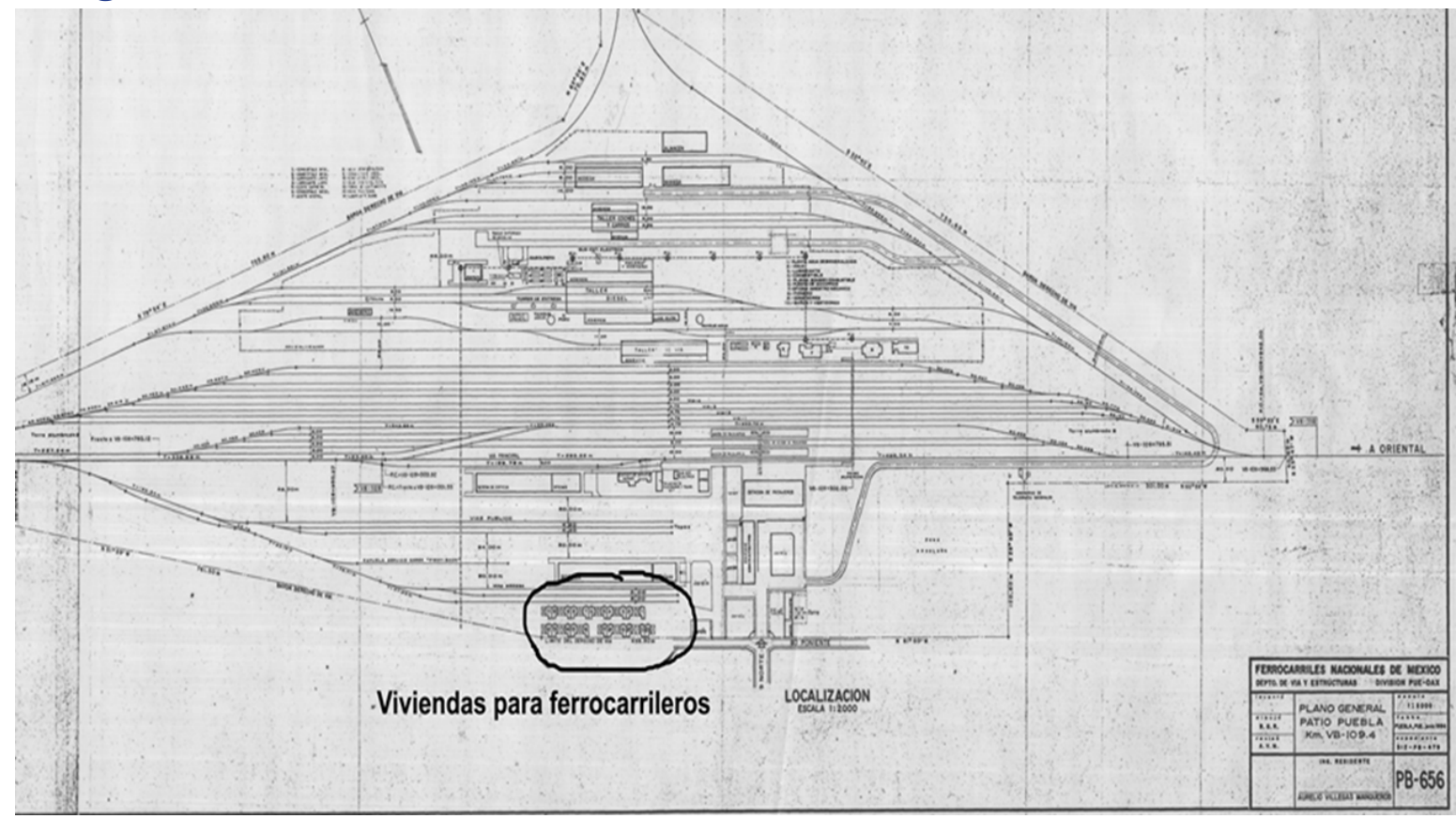

Fuente: Plano de Ferrocarriles Nacionales de México, 1984. Archivo CEDIF-MNFM-Conaculta.

\section{Ejes y atributos de centralidad}

A modo de sistematización se elaboró un modelo de registro que sintetiza los aspectos más relevantes que definen y caracterizan a las centralidades en nuestro contexto. Se toman como base diversos atributos, los que se agrupan según los siguientes ejes:

\section{Ambiente urbano y espacio público}

Constituye una de las claves para el estudio de estas áreas la elaboración de un diagnóstico de su contexto urbano en cuanto a sus características morfológicas y arquitectónicas y a los aspectos que refieren a la calificación del espacio público (diseño urbano, aceras, equipamiento, etcétera); también intervienen otros factores intangibles como lo son el volumen de tráfico, higiene, polución sonora, seguridad ciudadana, etcétera. La singular articulación e incidencia de cada uno de estos aspectos define la identidad de cada área urbana y determina la calidad ambiental de sus espacios públicos y por ende de la centralidad en su conjunto.

\section{Actividad, comercial y económica}

En cada uno de los casos se identifican la cantidad, características y rubro de los establecimientos comerciales comprendidos y se plantean indicadores relativos a densidad comercial y al peso relativo de los distintos formatos comerciales (comercio minorista, franquicias, cadenas, grandes superficies, etcétera). Se establece asimismo el grado de asociatividad comercial y la existencia o

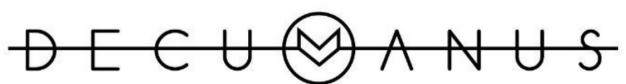

REVISTA INTERDISCIPLINARIA SOBRE ESTUDIOS URBANOS 
Figura 7. Líneas de ómnibus por centralidades

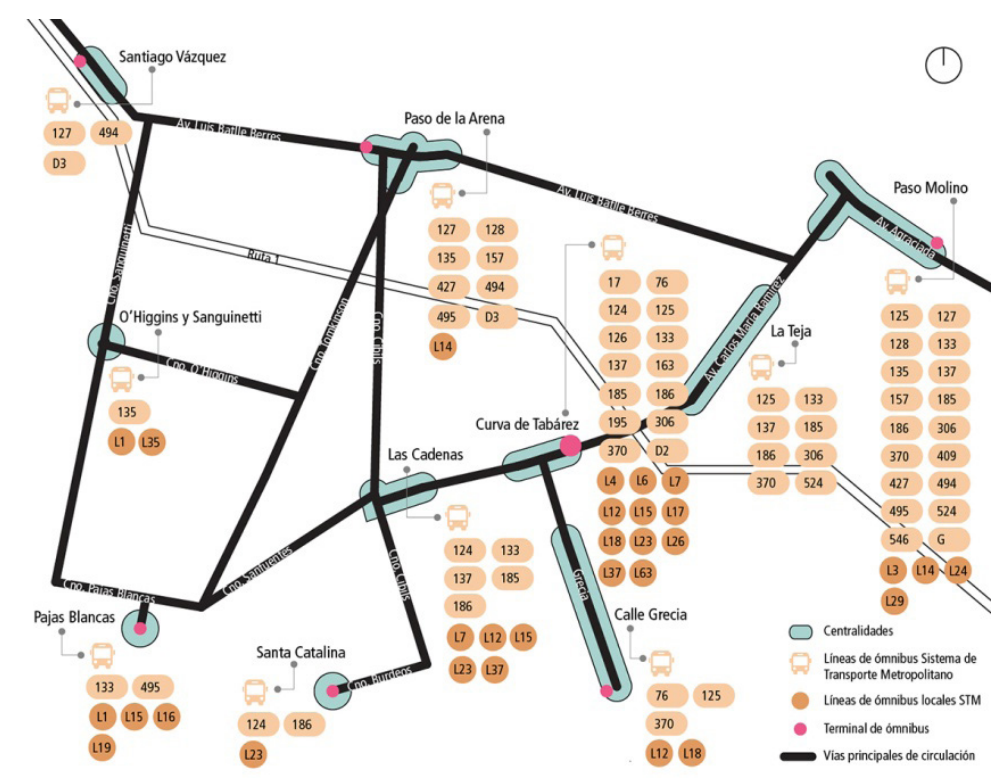

Fuente: Elaboración propia

no de iniciativas conjuntas por parte del colectivo de comercios. Para complementar esta perspectiva se busca determinar las principales actividades económicas de cada sector y su grado de vinculación con la actividad comercial y con la centralidad en términos generales. Se indaga en el vínculo entre las centralidades y las actividades industriales y logísticas que se desarrollan en el Municipio A.

\section{Equipamientos sociales y servicios públicos}

De acuerdo con lo que fue la conformación histórica de estas áreas urbanas, desempeñan un papel de primer orden en el desarrollo y el atractivo de ellas la presencia o no de oferta cultural y de ocio, así como la existencia de servicios y equipamientos públicos.
Constituye un objetivo de la investigación su identificación, mapeo y evaluación de su peso en la actualidad, así como sus potenciales roles en procesos de recuperación y revitalización de estas áreas.

\section{Movilidad}

Desde la perspectiva de la accesibilidad se promueve una mirada global relativa a las formas de acceso y desplazamiento hacia la centralidad, ya sean sistemas de transporte rodado colectivo o individual (motorizado o no) o áreas destinadas a la circulación peatonal.

Se establece como objetivo evaluar el rol y la calidad de los sistemas de movilidad y de los espacios destinados a ellos (localización de paradas de transporte colectivo, dotación adecuada de áreas peatonales, previsión de estacionamientos, accesibilidad desde áreas logísticas, etcétera).

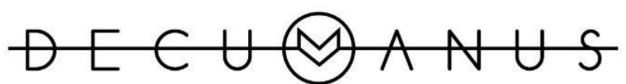

REVISTA INTERDISCIPLINARIA SOBRE ESTUDIOS URBANOS 
Figura 8. Paso de la Arena. Terminal de ómnibus

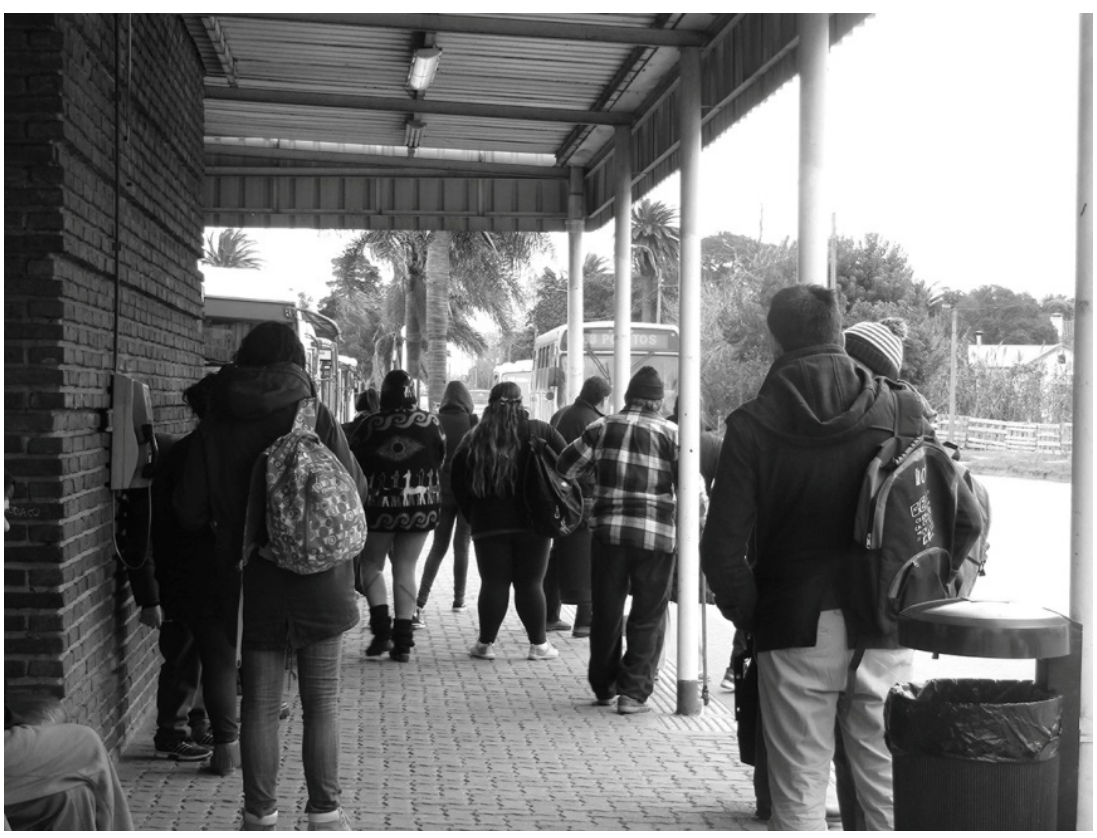

Fuente: Elaboración propia

\section{Identidad y rol simbólico}

Dado el relevante -e histórico- papel que estas áreas desempeñaron como centros de referencia de los barrios de la ciudad, se entiende imprescindible conocer cuál es el valor que estas comunidades locales les asignan en la actualidad a la luz de las importantes transformaciones que la ciudad ha experimentado en este terreno.

Indagar en este terreno permite establecer el grado de identificación y el sentido de pertenencia que estas centralidades generan, tanto entre la población de proximidad como en el conjunto de actores directamente involucrados.

A partir del análisis de los ejes y atributos de centralidad definidos se estructura un relato del proceso de conformación y escenario actual que presentan cada una de estas centralidades para conformar un mapa actualizado del sistema de centralidades según jerarquía, especificidad, delimitación y área de influencia donde se expliciten las diversas modalidades de interrelacionamiento y vinculación entre ellas.

\section{Construcción de una nueva mirada al Sistema de Centralidades}

Se presentan las conclusiones preliminares del Laboratorio de Centralidades Urbanas a la fecha de esta publicación, donde quedan planteadas temáticas que ya han sido consensuadas en el colectivo, y otras a indagar, para aportar a la construcción de una nueva mirada al Sistema de

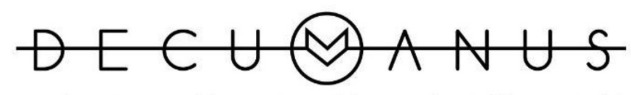

REVISTA INTERDISCIPLINARIA SOBRE ESTUDIOS URBANOS 
Centralidades del Área Metropolitana de Montevideo.

\section{Claves para comprender el} actual Sistema de Centralidades: el desarrollo del concepto de centralidad y su potencial como generador de derecho a la ciudad

La revisión del Sistema de Centralidades en la ciudad de Montevideo planteada como objetivo de esta investigación derivó en la necesidad de profundizar sobre la definición del término centralidad, término comúnmente acuñado en la jerga de la disciplina urbana, pero que frente a los procesos contemporáneos es necesario reelaborar, para que sea herramienta y soporte de acción en el territorio.

A partir de la Teoría de los lugares centrales (Christaller, 1933) en la que se enuncia que el territorio se organiza en espacios jerarquizados según el "superávit de servicios" que ofrecen, se desarrollan diversos conceptos de centralidad donde el foco común se pone en la definición como lugar atractor de personas donde se producen elevados intercambios.

A partir de la década del setenta esta definición basada en criterios con predominancia de flujos económicos se revisó con los aportes de autores desde las ciencias sociales como Henri Lefebvre (1969), entre otros, que ponen el foco en las relaciones sociales que le dan sentido y coherencia a dichos espacios dentro de la trama de la ciudad.

En las últimas décadas surgen posiciones que explicitan la riqueza de las centralidades como "espacios multifuncionales de diferentes escalas, con un rol definido, que atraen personas y bienes en donde se producen intensos intercambios colectivos" (HYDEA-Target Euro, 2008). Se identifican en ellas "i) una alta concentración de servicios y actividades de diferentes escalas que determinan su grado de atracción de personas; ii) buena accesibilidad interna y desde el resto de la ciudad (suelen tener nodos de transporte); y iii) el reconocimiento de la comunidad como el centro de la zona a la que pertenecen, siendo un punto de referencia y de expresión simbólica de las condiciones de vida de sus habitantes" (Cuenin y Silva, 2010).

Frente al fenómeno de globalización y expansión urbana en América Latina aparecen nuevos lugares de consumo que tienen la capacidad de ser atractores para la población, definiendo nuevas relaciones temporal-espaciales.

Para comprender el actual Sistema de Centralidades nos afiliamos al trabajo de Paris (2013), el cual retoma la clasificación de funciones centrales de otros autores e identifica-las centralidades tradicionales, centralidades emergentes y lo que define como "lugares de centralidad".

Los centros o centralidades tradicionales son aquellos que corresponden a espacios simbólicos que se han consolidado a lo largo del tiempo, vinculados a las trazas originarias o con los posteriores crecimientos de la

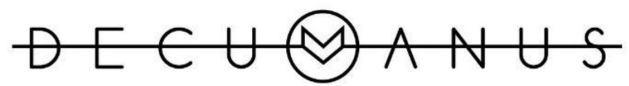

REVISTA INTERDISCIPLINARIA SOBRE ESTUDIOS URBANOS 
Tabla 1. Clasificación de las funciones centrales

\begin{tabular}{|c|c|c|c|c|}
\hline & \multicolumn{4}{|c|}{ Agrupación } \\
\hline \multirow{2}{*}{ Localización } & Funciones aisladas & $\begin{array}{c}\text { Centralidades } \\
\text { homogéneas }\end{array}$ & $\begin{array}{c}\text { Centralidades } \\
\text { heterogéneas }\end{array}$ \\
\cline { 2 - 5 } & $\begin{array}{c}\text { Dispersos en el } \\
\text { territorio } \\
\text { Cruces de } \\
\text { infraestructuras }\end{array}$ & $\begin{array}{c}\text { Monofunciones } \\
\text { modernas } \\
\text { Monofunciones } \\
\text { modernas }\end{array}$ & Polígonos/Polos & $\begin{array}{c}\text { Centros } \\
\text { tradicionales }\end{array}$ \\
\begin{tabular}{c|c|c|c|} 
Centralidades \\
emergentes
\end{tabular} \\
\hline
\end{tabular}

Fuente: Paris, 2013.

ciudad, donde se mixturan en la traza pueblos o villas que se encontraban fuera de los trazados originales y que reproducen el mismo esquema de centro para su área de influencia, siendo el valor identitario y la predominancia del espacio público (plazas en algunos casos o la calle misma) de ellos una característica distintiva donde se condensan intensos intercambios.

Las centralidades emergentes están dispersas en el territorio, caracterizadas por un "alto grado de accesibilidad que atraen y estimulan a sus propios usuarios/consumidores" (Paris, 2013), donde se agrupan funciones sin aún consolidarse en el imaginario colectivo, siendo espacios diseñados en arquitectura contemporánea con potencialidad de generar nuevas propuestas de espacios de interacción.

Los lugares de centralidad exacerban un fenómeno del cual el propio Lefebvre en la década del setenta ya advertía:

[...] la centralidad urbana puede ser un lugar integrador para los ciudadanos más pobres, que con- crete su derecho a la ciudad, en la medida en que allí se dan una multiplicidad de usos y de interacciones sociales. Pero Lefebvre insiste en que la centralidad en la ciudad capitalista muy a menudo no juega este papel sino que contribuye a diferenciar los espacios urbanos, lo que genera fenómenos de exclusión (Beuf, 2011).

Son espacios híbridos y complejos donde hay edificios -contenedores y espacios libres- gestionados por privados donde se dan las interacciones contemporáneas, comúnmente vinculadas al consumo. Por lo cual el espacio y la acción son controlados, lo que socava la esencia del espacio de socialización de carácter público como lugar de encuentro y manifestación de las contradicciones que la propia comunidad tiene, y agudiza los procesos de segregación socioespacial.

La clave del espacio público y la cogestión entre actores parece ser una apuesta y desafío a ser encarados para repensar el sistema de centralidades en nuestro contexto metropolitano por medio de la indagación de cuáles son los roles y re-

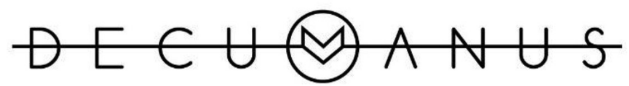

REVISTA INTERDISCIPLINARIA SOBRE ESTUDIOS URBANOS 
laciones de los centros de consumo, las centralidades tradicionales, y los posibles proyectos de nuevas centralidades emergentes en el territorio para contribuir al derecho de toda la ciudadanía.

\section{Repensar el Sistema de}

\section{Centralidades en clave}

\section{metropolitana}

Vinculado a los procesos de desplazamiento de la población desde las áreas consolidadas a la periferia del área metropolitana asistimos en los últimos veinte años a la aparición de grandes equipamientos de consumo (Centro Cívico de la Costa, Shopping Center de las Piedras) y lugares de centralidad como Zonamérica y el Aeropuerto Internacional de Carrasco. Ante esta constatación, a la vez que nos focalizamos en el estudio de las centralidades del Municipio A, no se soslaya la necesidad de la mirada territorial más amplia, ya que las centralidades funcionan como sistema. En esa dirección las Estrategias Regionales de Ordenamiento Territorial y los Planes Interdepartamentales son instrumentos de ordenamiento territorial (IOT) adecuados para trabajar la temática de centralidades en clave metropolitana. Si bien el Área Metropolitana de Montevideo tiene aprobadas sus Estrategias Regionales donde se arriba a algunos consensos, aún no hay Planes Interdepartamentales en elaboración. Por otra parte, debe recordarse que la Ley de Ordenamiento Territorial y Desarrollo Sostenible (LOTDS) es una "ley joven", con tan solo diez años de aprobada.

\section{Estrategias de intervención para trabajar en una policentralidad variada}

Del avance del trabajo se desprende como conclusión preliminar la necesidad de diferenciar diversas estrategias de intervención entre las centralidades definidas en el POт en 1998 en el oeste de Montevideo.

Por un lado, se detectan casos donde se hallan elementos preexistentes valiosos (aspectos urbanos, históricos, área comercial consolidada, espacios públicos calificados, equipamientos), donde la estrategia propuesta es explorar proyectos de carácter integral con el objetivo de fortalecer la identidad en cada una de las centralidades, poniendo en valor la impronta que le da carácter e interés en la escala metropolitana. Ejemplos de ello son el potencial de Santiago Vázquez vinculado a los variados espacios públicos de calidad en el entorno del río Santa Lucía como espacio de ocio a nivel metropolitano; el caso de Pajas Blancas y su vinculación al acceso a la playa en el oeste de Montevideo, y la característica de centralidad de Interfase Rururbana de Paso de la Arena.

Por otra parte, se observa en el ámbito del Municipio A territorios enclavados, categorizados como Suelos Suburbanos Habitacionales donde los IOT vigentes no identifican centralidad alguna. En próximas etapas el Laboratorio se propone evaluar la pertinencia de centralidades de jerarquía local en estos enclaves. Se hace referencia concretamente a La Colorada, Barrio Gori, Cabaña Anaya, Barrio Nuevo Lamas, Los Bulevares.

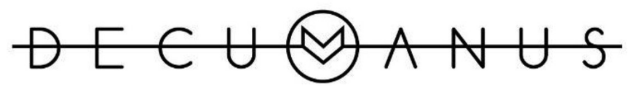

REVISTA INTERDISCIPLINARIA SOBRE ESTUDIOS URBANOS 
Asimismo se constató que lugares definidos como centralidades en la normativa vigente no tienen o han perdido los atributos definidos como esenciales por este equipo, por lo cual se propone profundizar en el marco de esta investigación cuáles son las herramientas de gestión pertinentes para su abordaje.

\section{Escenario actual de las centralidades en el Municipio A}

Desde el punto de vista de la categorización del suelo, las doce centralidades urbanas del Municipio A se ubican en suelo subcategoría Urbano Consolidado Intermedio y suelo Urbano No Consolidado según el caso, con la salvedad de Santiago Vázquez, subcategorizado como suelo Urbano Consolidado Otros. Desde el punto de vista de la distribución en la trama, la situación puede ser en continuidad -situaciones intermedias o de borde- o en enclaves, rodeadas de suelo rural. Esta última es la condición de Santa Catalina, Pajas Blancas y Santiago Vázquez.

La situación de estas centralidades urbanas enclavadas tiende a una lógica de mayor aislamiento, con una vocación de concentrar servicios de proximidad y abastecimiento cotidiano esenciales. Presentan una situación de cierto estancamiento.

Paradójicamente, la centralidad rural de Sanguinetti y O'Higgins posee servicios educativos -escuela y liceo- que la destacan en ese aspecto respecto de las centralidades urbanas próximas.

Entre las centralidades en el continuum de la trama urbana se cons- tata un mayor dinamismo relativo e interacción que se expresa en mayor presencia comercial y de servicios. Generan procesos de expansión sobre los principales conectores y arterias viales.

Dichas continuidades conforman fenómenos de conurbación comercial de baja densidad que llegan a conectar varias de estas centralidades entre sí. Esta situación puede apreciarse en el corredor conformado en torno a los ejes avenida Agraciada y Carlos María Ramírez, donde el proceso de expansión del Paso Molino hacia Belvedere provoca una conexión con la centralidad de La Teja, la que a su vez (con pequeñas interrupciones) conecta con Curva de Tabárez, y esta última con el Eje Grecia.

Mediante el mapeo de actividad comercial de dicha continuidad de centralidades a partir de corredores de circulación puede apreciarse cómo la densidad de establecimientos comerciales presenta variaciones de 60 comercios por cuadra (Paso Molino) hasta 10 (Carlos María Ramírez o Grecia).

Las densidades, perfiles y rubros de las áreas comerciales, al igual que la presencia de equipamientos y servicios, continúan estableciendo en la red de centralidades relaciones de jerarquía que definen el tipo de vínculos que estas mantienen entre sí. Desde esta perspectiva puede apreciarse en el conjunto del Municipio A, dos encadenamientos de centralidades confluyentes al Paso Molino, asociados por vínculos de proximidad y dependencia: Santiago Vázquez/Paso de la Arena/Paso Molino y Santa Ca-

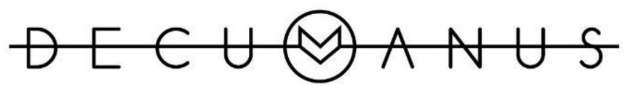

REVISTA INTERDISCIPLINARIA SOBRE ESTUDIOS URBANOS 
Figura 9. Estudio sobre vínculos y jerarquías existentes entre las centralidades del Municipio A

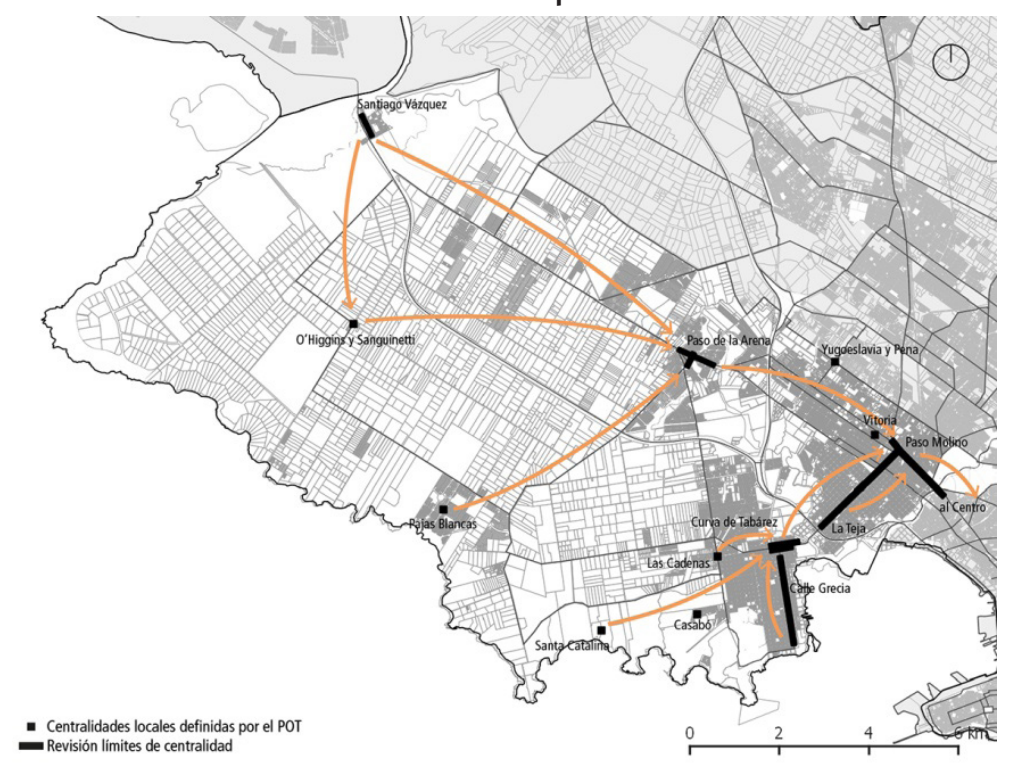

Fuente: Elaboración propia en base a cartografía SIG, Intendencia de Montevideo

talina/Las Cadenas/Curva de Tabárez /Paso Molino.

Esta lógica de interrelación tiende preponderantemente a una intensificación de flujos confluyente a las centralidades de mayor dimensión que cuentan con equipamiento más variado. Se debe tener en cuenta los posibles conflictos que la mayor densidad comercial puede tener en debilitar actividades de ocio si no se realiza una gestión coordinada entre públicos y privados.

Esta configuración de centralidades, que pareciera no presentar grandes variantes en las últimas dos décadas, se enfrenta en la actualidad a un nuevo escenario pautado por la implantación de posibles lugares de centralidad como la Unidad Alimentaria (UAM) o el proyecto del Puerto de Punta Yeguas.

Como respuesta a los desafíos de este nuevo contexto se entiende re- levante destacar políticas y proyectos implementados desde el ámbito público, que directa o indirectamente pueden contribuir al posicionamiento y revitalización de estas tradicionales centralidades como el Plan Parcial de la cuenca del Pantanoso, los lineamientos en la Microrregión de Santiago Vázquez, el proyecto de Nodos Urbanos de Calle Grecia y la gestión entre vecinos e Intendencia Departamental de Montevideo del parque Punta Yeguas.

\section{Gestión de las centralidades y nuevos desafíos}

La condición de singularidad de las centralidades como ámbitos en los que confluyen y yuxtaponen de manera múltiple, actividades humanas, flujos económicos y servicios, es lo que convierte estas áreas en sectores de la ciudad tan relevantes como

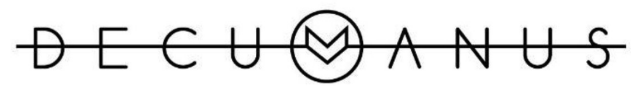

REVISTA INTERDISCIPLINARIA SOBRE ESTUDIOS URBANOS 
Figura 10. Estudio sobre cantidad de pobladores (consumo de cercanías o cotidiano) por cada centralidad del Municipio A. Graficado esquemáticamente según ubicación y tamaños relativos

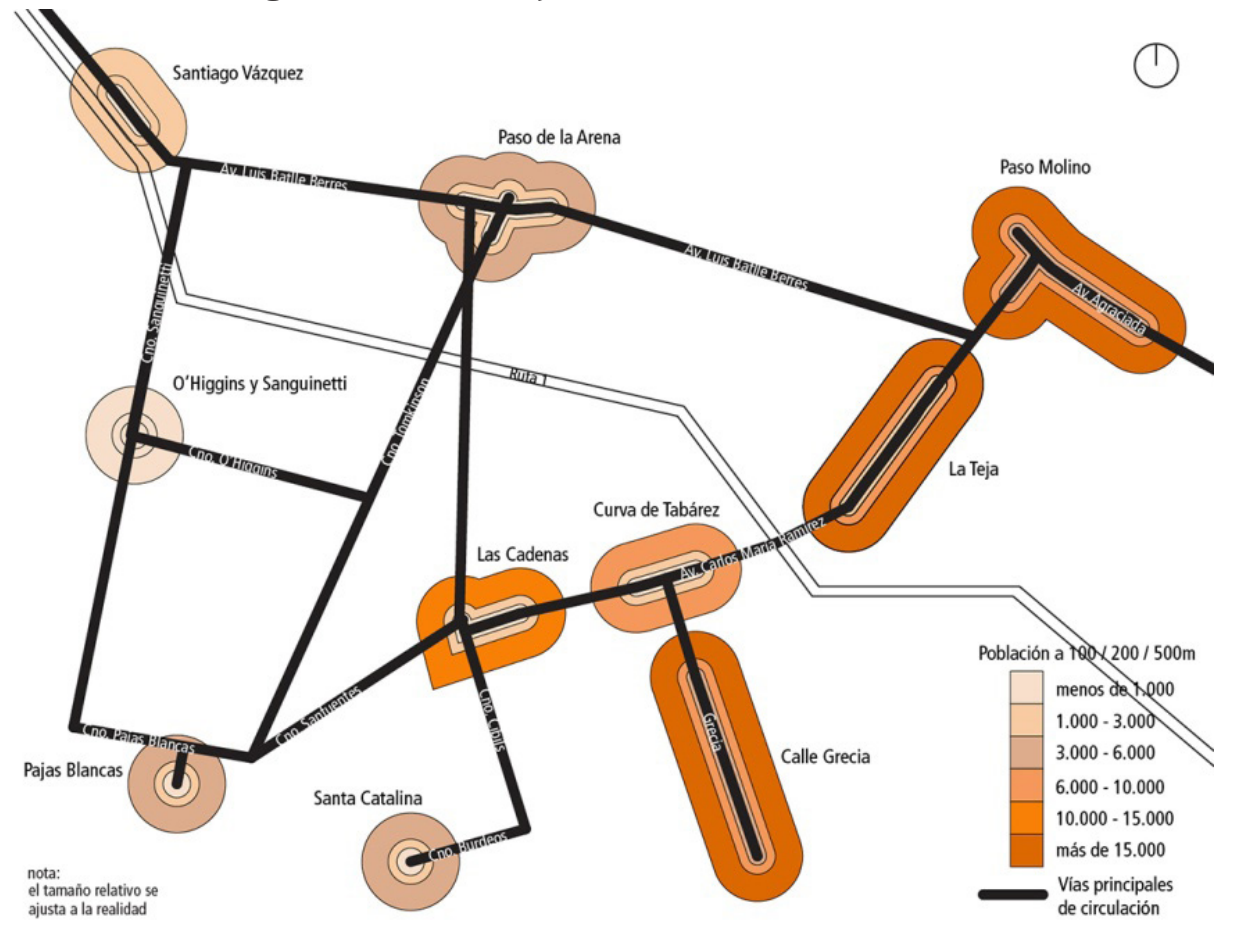

Fuente: Elaboración propia

complejos. Su condición de escenarios de la vida pública - accesibles universalmente- ponen en juego de forma natural y cotidiana aspectos esenciales a la vida urbana en comunidad, como lo son el ejercicio de la tolerancia y el equilibrio entre las libertades, responsabilidades individuales y consensos colectivos.

En ese sentido y desde la perspectiva del derecho a la ciudad entendemos que esa diversidad/complejidad no constituye un escenario a ser depurado o superado, sino que se trata de aspectos que hacen a la esencia de estas centralidades urbanas y que por tanto, deberán ser reconocidos, jerarquizados y adecuadamente administrados.

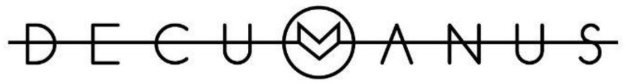

REVISTA INTERDISCIPLINARIA SOBRE ESTUDIOS URBANOS
El énfasis en este aspecto se relaciona con la preocupación ante la expansión del modelo de consumo impuesto por los centros comerciales cerrados y por la necesidad de consolidar otros paradigmas compatibles con las políticas de inclusión social, sustentabilidad y acceso democrático a la ciudad.

El extendido énfasis en la condición de espacios cerrados y en la indiferencia urbana que reflejan las lógicas arquitectónicas de estos grandes equipamientos puede hacer perder de vista otros aspectos aún más relevantes implícitos en este modelo, como es la reducción de nuestra condición de ciudadanos a simples consumidores y la renuncia a esa libertad responsable que ha fundado 
históricamente la convivencia en el ámbito público de la ciudad.

La necesidad de hacer frente a estos desafíos ha conducido internacionalmente al desarrollo de estrategias dirigidas a una gestión compartida de estos centros urbanos que buscan el consenso y la articulación del conjunto de actores públicos y privados territorialmente involucrados. Estos modelos apuntan a un abordaje "integral" de las centralidades, comprenden y administran el conjunto diverso de operadores implicados, las características y particularidades del entorno urbano y la complejidad de actividades que en él acontecen.

Se señalan como experiencias de referencia a nivel mundial en este sentido los modelos de Town Centre Management (Gestión de Centros Urbanos) desarrollado en el Reino Unido y el modelo norteamericano de Business Improvement Districts (Distritos de Dinamización Empresarial). Estos modelos -sustentados en lógicas de gestión, estatutos jurídicos, estructuras organizativas y mecanismos de financiación bien diferentes- han logrado aportar al posicionamiento comercial de estos centros y a la recuperación de áreas urbanas significativas. Se implementan acciones centradas en accesibilidad, limpieza, mantenimiento, equipamiento urbano, animación cultural, promoción del asociacionismo, etcétera. La incorporación y adaptación de estos modelos por parte de otros países ha dado lugar a su vez a otras experiencias relevantes como la promovida por la Asociación Española para la Gerencia de Centros (AGECU) o la desarrollada más cerca en la región, por la Federación de Centros Comerciales a Cielo Abierto, Cascos Urbanos y Centros Históricos (Confederación Argentina de la Mediana Empresa, CAME), también citados por Lorena Vecslir y otros (2018).

La referencia a estos modelos y prácticas no tiene como objeto un análisis o evaluación particular (cuyo abordaje excedería los alcances actuales de la investigación), sino el indicar que existe ya desde hace varias décadas una amplia experiencia internacional que habla de la necesidad de contar con modelos o estrategias de gestión que respondan de manera integral a la realidad que enfrentan estas áreas urbanas. Se superan asi los abordajes parciales y las prácticas "espontáneas" que guiaron su funcionamiento tradicionalmente.

Constituye una fiel expresión de la desactualización que experimenta esta temática en nuestro medio el hecho de que los casos estudiados no cuenten con experiencias organizadas de gestión de la centralidad y -en el caso del Municipio A- solamente en el Paso Molino existe una asociación comercial formalmente constituida (aspecto relevante dado el papel de liderazgo que le ha competido a estas organizaciones en las experiencias señaladas). Es significativo que tampoco en las demás centralidades de Montevideo en las que existen asociaciones comerciales se verifican experiencias de este tipo, constituyendo como única excepción el caso del Centro de Montevideo, donde se estableció un convenio entre la Intendencia de Montevideo y la Asociación Comercial Grupo Centro que apunta al desarrollo de un pro-

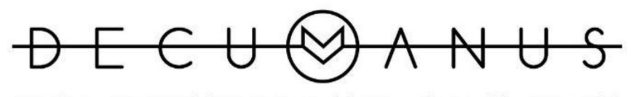

REVISTA INTERDISCIPLINARIA SOBRE ESTUDIOS URBANOS
Núm. 4. Vol. 4. Octubre 2018-Octubre 2019.

Instituto de Arquitectura, Diseño y Arte.

Universidad Autónoma de Ciudad Juárez. ISSN: 2448-900X 
ceso de revitalización y a la conformación de un ámbito de gestión permanente, con promoción de acciones integradas en las de áreas de movilidad, espacio público, equipamiento urbano, ordenamiento de venta callejera, adecuación de cartelería comercial, etcétera.

Se plantea como hipótesis que esa escasa relevancia que la temática ha tenido en nuestro medio responde en gran medida a la invisibilidad que experimentan las centralidades como parte de ese conjunto de fenómenos culturales cotidianos, cuya supervivencia se considera de alguna forma natural o inexorable y ajena, por tanto, a los devenires y transformaciones de la ciudad y la sociedad. Dichas inercias han constituido un impedimento para comprender y dimensionar los alcances de las transformaciones que - desde al menos tres décadas- experimentan estas áreas urbanas a nivel global, comprometiendo su futuro y desconociendo su contribución al desarrollo de centros urbanos inclusivos y democráticos.

Entre los desafíos que supone este abordaje se encuentra la búsqueda de respuestas a la convivencia y conflicto entre la economía formal e informal, a las políticas de densificación y las problemáticas de vivienda, al acceso de los emprendimientos de pequeña y mediana escala, a las problemáticas de seguridad pública y convivencia.

Dadas las características socioculturales y urbanas que presenta el Municipio A, las políticas y acciones que pudieran implementarse en esta línea no solo contribuirían a ese posicionamiento y a la concreción de nuevas experiencias, sino que permitirían ampliar y enriquecer el instrumental con el que la ciudad afronta sus desequilibrios territoriales y los procesos de desintegración social.

\section{Referencias bibliográficas}

Almeida dos Santos, S. (2015). Bom Jesus da Lapa-BA na rede urbana regional e os circuitos da economia. [Tesis de Maestría en Geografía]. San Pablo: Universidad Estatal de Campinas (UNI(AMP).

Beuf, A. (2011). Nuevas centralidades y acceso a la ciudad en las periferias bogotanas. Boletín del Instituto Francés de Estudios Andinos, (40)1, 147-78. DOI: $10.4000 /$ bifea.1663.

Christaller, W. (1966). Central Place in Southern Germany (trad. de C.W. Baskin). Englewood Cliffs, New Jersey: Prentice-Hall Inc. Primera publicación Alemania, 1933.

Cuenin, F. y Silva, M. (2010). Identificación y fortalecimiento de Centralidades Urbanas: El Caso de Quito. Banco Interamericano de Desarrollo. Notas Técnicas IDB-TN-156.

HYDEA-Target Euro (2008). Programa de Fortalecimiento del Sistema de Centralidades Urbanas de Quito (ECL1041). Informe Final de Consultoría.

Gehl, J. (2013). La humanización del espacio urbano (EUA09). La vida social entre los edificios. Barcelona: Editorial Reverté.

Harvey, D. (1977). Urbanismo y desigualdad social. España: Editorial Siglo XXI. Jacobs, J. (1967). Muerte y vida de las grandes ciudades. Madrid: Ediciones Península.

Lefebvre, H. (1969). El derecho a la ciudad. Barcelona: Ediciones Península.

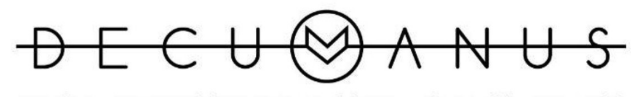

REVISTA INTERDISCIPLINARIA SOBRE ESTUDIOS URBANOS 
Publicación original: Le detroit a la ville (1968). París: Editions Anthropos.

Panerai, P. (coord.) (1983). Elementos de análisis urbano. Madrid: Instituto de Estudios de Administración Local.

Paris, M. (2013). De los centros urbanos consolidados a los lugares de centralidad: una propuesta metodológica para su estudio. Dossier Monográfico Ciudades, (16). Recuperado de http://uvadoc.uva.es/bitstream/10324/10345/1/ CIUDADES-2013-16-DELOSCENTROS.pdf

Rogers, R. (2000). Ciudades para un pequeño planeta. Barcelona: G. Gili.

Rovira Lara, A. (2000). Propuesta y modelos para la gestión estratégica de los centros urbanos desde la cooperación pública y privada. Revista Gestión y Análisis de Políticas Públicas (GAPP), 19, 19-34, España.

Sabaté, J. (2004). Paisajes culturales. El patrimonio como recurso básico para un nuevo modelo de desarrollo. Revista Urban, 9. Departamento de Urbanística y Ordenación del Territorio. Escuela Técnica Superior de Arquitectura. Universidad Politécnica de Madrid. Edición Anta Ediciones.

Urruzola, J. P. (1994). Nuevas centralidades o viejos problemas. Revista Elarqa, (4)12. Montevideo: Editorial Dos Puntos SRL.

Vecslir, L., Blanco, J., Nerome, M., Sciutto, F., Maestrojuan, P. y Rodríguez, L. (2018). Un corredor sin autopista. Centralidad y movilidad cotidiana en el sur de la Región Metropolitana. Buenos Aires: Café de las Ciudades.

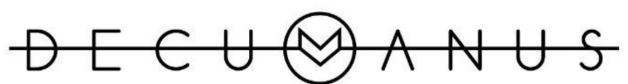

REVISTA INTERDISCIPLINARIA SOBRE ESTUDIOS URBANOS 